\title{
Drug history taking and the identification of drug related problems in an accident and emergency department
}

\author{
I Akwagyriam, L I Goodyer, L Harding, S Khakoo, H Millington
}

\begin{abstract}
Objective-To determine the incidence of drug related problems that fail to be noted on casualty cards in patients subsequently admitted, and to compare medication histories as recorded by accident and emergency (A\&E) senior house officers (SHOs) and a pharmacist.

Methods-An initial retrospective survey of 1459 acute inpatient admissions through A\&E over a three month period was followed by a prospective study of 33 elderly patients.

Results-In the retrospective survey, 52 medication related problems were confirmed after examination of the medical records, of which only 16 were identified in A\&E. In the prospective study, 125 currently prescribed items were identified by the pharmacist compared to 77 by A\&E SHOs; $66 \%$ of the missed information was clinically relevant. Of 17 previous adverse drug reactions identified by the pharmacist only six were also recorded by the A\&E officer. Only four over the counter medicines were identified by the $A \& E$ SHOs compared to 30 by the pharmacist. Conclusions-More accurate recording of drug history on casualty cards should be undertaken, particularly in respect of over the counter medication and the identification of drug related problems.

( $\mathcal{A}$ Accid Emerg Med 1996;13:166-168)
\end{abstract}

Key terms: drug history taking; elderly patients; drug related problems

Department of

Pharmacy, King's

College London,

London SW3

I Akwagyriam

L I Goodyer

S Khakoo

Accident and

Emergency

Department, Charing

Cross Hospital,

London W6

H Millington

Pharmacy

Department, Charing

Cross Hospital,

London W6

L Harding

Correspondence to:

Dr L I Goodyer,

Department of Pharmacy,

King's College London,

Manresa Road

London SW3 $6 \mathrm{LX}$

United Kingdom. ding physician at the same time as a patie history, although errors of om have been described in $10 \%-20 \%$ of hospital records. ${ }^{34}$ Several studies ${ }^{5-11}$ have shown that pharmacists can elicit a more complete history than physicians, and can devote more time to this activity. The incidence of errors in drug history taking within an $A \& E$ department has not been reported before.

In the first part of this study we investigated drug related problems retrospectively among people presenting to an $\mathrm{A} \& \mathrm{E}$ department and subsequently admitted as inpatients, by examining the drug histories taken by the $A \& E$ senior house officer (SHO). In a second part we attempted further quantification of potential drug related problems which may have been missed due to incomplete history taking, by comparing drug histories taken by $A \& E$ SHOs to those taken by a pharmacist.

\section{Methods}

First, a retrospective analysis of $A \& E$ cards was undertaken at Charing Cross Hospital, London, over a three month period for all patients attending the department who were subsequently admitted as medical inpatients. Patients admitted because of intentional or accidental overdose, poisonings, or substance abuse were not included. The cards were screened for potential drug related problems by examining the drug history as recorded by the $A \& E$ SHO. The identification process was performed to a list of specific criteria shown in table 1 . The medical records of these patients were then screened to identify those drug related problems which were of clinical significance. This was judged to be the case if specific mention was made in the notes, or as in a few cases, if the clinical evidence was strong enough to confirm the problem. A note was made of the point in the patient's admission and by whom the drug related problem was identified. The findings of the pharmacist surveying the records were validated by a second, independent, clinical pharmacist.

For the second part of the study elderly patients were interviewed by a pharmacist using a structured questionnaire to ascertain

Table 1 Criteria for potential drug related problems

Adverse drug reaction or allergy

Contraindication

Dosage problems

Prutients over the age of 60 years on multiple drug treatment where there were potential compliance problems

Elderly patients taking drugs which may have contributed to a fall (eg, CNS, antihypertensive)

Drugs which had not been properly identified mentioned on A\&E card

Any drug related problem identified by A\&E SHO 
current prescribed medication, over the counter usage, and adverse drug reactions. All elderly patients ( $>70$ years) were included except those who could not give a coherent history, for example those who were unconscious or confused. In addition those admitted and discharged overnight could not be included. The study was conducted over a six week period and patients were interviewed either in the $A \& E$ department or in $A \& E$ ward, after they had been seen by the A\&E SHO. The notes made by the A\&E SHO for each patient were reviewed and details regarding drug history recorded. A letter was sent to the patients' general practitioner (GP) requesting full details of current drug treatment. At the end of the study all differences in drug history between the pharmacist and A\&E SHO were peer reviewed by a panel to identify any examples of possible clinical significance.

Statistical analysis was performed using the $\chi^{2}$ test for the retrospective study and MannWhitney $U$ test for the drug history taking study.

\section{Results}

RETROSPECTIVE STUDY

In all, $1459 \mathrm{~A} \& \mathrm{E}$ cards were screened, and of these $182(12.5 \%)$ had potential drug related problems. Of these, $52(3.5 \%)$ were confirmed after examination of the medical records. Seventeen of these $(37 \%)$ were identified in A\&E. Eight drug related problems were not identified at any stage by medical staff, but in the opinion of the research pharmacists contributed to admission. Thirty eight patients $(73 \%)$ with a confirmed drug related problem were aged 65 years or over, and nine of these presented with a fall. The data in table 2 were recoded to combine the point of identification as either in $A \& E$ or on the ward, and the type of drug related problem as adverse effect/ allergy, non-compliance, or other problem. When classified in this way there was a significant association between the type of drug related problem and the point of identification $(\mathrm{P}<0.001)$.

The allergic reactions were well recorded by the A\&E SHOs. They included photosensitivity to amiodarone and an allergic dermatitis to dapsone. Also well documented on the $A \& E$ cards were suspicions of poor compliance, in two instances concerning discontinuation of antiepileptic drugs leading to fits. Adverse effects were less well documented. Examples included obvious movement disorders due to neuroleptics, nausea and vomiting experienced

Table 2 Numbers of patients with confirmed drug related problems and point of identification

\begin{tabular}{lrllll}
\hline $\begin{array}{l}\text { Type of } \\
\text { drug related } \\
\text { problem }\end{array}$ & $\begin{array}{l}\text { Total } \\
\text { identified }\end{array}$ & $\begin{array}{l}\text { Identified } \\
\text { in A E E }\end{array}$ & $\begin{array}{l}\text { Identified } \\
\text { on clerking }\end{array}$ & $\begin{array}{l}\text { Identified } \\
\text { after clerking }\end{array}$ & $\begin{array}{l}\text { Not } \\
\text { identified }\end{array}$ \\
\hline Allergy & 5 & 4 & 1 & 0 & 0 \\
C/I & 4 & 1 & 2 & 1 & 0 \\
Dosage & 6 & 1 & 4 & 1 & 0 \\
S/E & 23 & 2 & 5 & 12 & 4 \\
N/C & 9 & 8 & 1 & 0 & 0 \\
D/I & 5 & 0 & 0 & 1 & 4 \\
Total & 52 & 16 & 13 & 15 & 8 \\
\hline
\end{tabular}

C/I, contraindication; S/E, side effects; N/C, non-compliance; D/I, drug interactions.
Table 3 Comparison of drug histories taken by a pharmacist and $A \mathcal{E} E S H O$

\begin{tabular}{lrr}
\hline & Pharmacist & $\begin{array}{l}A \mathcal{E} E \\
\text { SHO }\end{array}$ \\
\hline $\begin{array}{l}\text { Number of currently prescribed drugs } \\
\text { identified }\end{array}$ & 125 & 77 \\
$\quad$ Dose/strength noted & 120 & 29 \\
$\quad$ Starting date noted & 107 & 0 \\
Number of previously prescribed drugs & 24 & 3 \\
identified & 33 & 4 \\
Over the counter drugs identified & 17 & 6 \\
Previous adverse drug reactions reported & 17 & \\
\hline
\end{tabular}

by patients prescribed erythromycin, falls among elderly patients taking antihypertensives, and non-steroidal anti-inflammatory drug (NSAID) induced bleeding resulting from over the counter medication. Potential interactions, for instance in a patient prescribed both cimetidine and theophylline, were poorly recorded throughout. Dosage problems, such as in elderly patients on high doses of hypnotics, were well screened during clerking on the wards. Thirty five $(68 \%)$ of the drug related problems related to drugs acting on the central nervous system (that is, anticonvulsants, antidepressants, and antipsychotics), 10 $(20 \%)$ to cardiovascular medication, six (11\%) to antibiotics, and five ( $9 \%$ ) to NSAIDs.

DRUG HISTORY TAKING STUDY

Thirty three elderly patients [mean age 80 (SD 5.81 ) years] were interviewed, each interview lasting on average $11.8(5 \cdot 8)$ minutes. Table 3 shows the difference in records made by the pharmacist and A\&E SHO. The pharmacist identified significantly more $(P<0.05)$ medications per patient (median $=3, Q 1=2$, $\mathrm{Q} 3=6$ ) than the $\mathrm{A} \& \mathrm{E} \mathrm{SHO}$ (median $=2$, $\mathrm{Q} 1=0, \mathrm{Q} 3=4)$. Only 13 replies were received from the GPs, who were able to supply nine drug histories, recording a median of four $(\mathrm{Q} 1=3, \mathrm{Q} 3=6)$ drugs per patient.

In total 24 patients had one or more omission in their drug history, both prescribed and over the counter, according to the pharmacist. In only three cases was a drug identified by the A\&E SHO that was not noted by the pharmacist.

From the peer review the extra information gained by the pharmacist was felt to be of no clinical relevance to the admission in 12 cases $(37 \%)$, while in seven $(22 \%)$ it provided some useful background information, in seven $(22 \%)$ it may have been relevant when further drugs were prescribed, and in six $(19 \%)$ the drug problems identified may have contributed to the need for admission.

\section{Discussion}

In our retrospective study we examined drug related problems which were apparent from the medication history as taken by the A\&E SHO and at what stage after admission the drug related problem was actually identified. The incidence of drug related problems is highest among drugs acting on the CNS, which may be expected when considering the age of the patients in this study. ${ }^{12}$ The A\&E SHOs appear more vigilant in detecting allergies and noncompliance than problems such as drug interactions and other side effects. We cannot 
exclude the possibility that A\&E SHOs identified the problems without making a record on the patients' cards, although this would not be considered good practice. Even though many problems were picked up by physicians on the ward, in some cases they were missed on initial clerking and in others overlooked altogether.

In the second part of the study we attempted to identify drugs that were not noted during routine clerking by an A\&E SHO. Since the retrospective study contained a high proportion of elderly patients, the prospective study was conducted on this age group.

A study by Dodds ${ }^{4}$ on inpatients found a somewhat lower rate of omission $-33 \%$ compared with the $62 \%$ in our study. Accurate drug history taking is arguably even more important in the $\mathrm{A} \& \mathrm{E}$ environment in those patients discharged or admitted to an observation ward under the sole care of the $A \& E$ department, as there is less time than for inpatients for assessment and liaison with the patient's GP and relatives to gain an accurate history. The majority of the adverse reactions reported were to antibiotics, and where both pharmacist and A\&E SHO had recorded the reaction there was no discrepancy.

It may be asked whether the pharmacist or the A\&E SHO actually took the more accurate history. Because of the poor response from the GPs, their records could not be used as a standard against which the others could be assessed, and the accuracy of GP records may also be questioned. ${ }^{5}$ As the pharmacist used a combination of extensive patient interview and other sources of information, it may be assumed that a high proportion of the omissions noted by the pharmacist were true.

The incidence of clinically significant differences in the drug histories obtained is somewhat higher than in studies conducted in other clinical settings, which showed no statistical difference $^{9}$ and differences in $11 \%$ of cases reviewed. ${ }^{7}$ The six cases in the present study where the missed information was felt to be important to the current admission contained a range of possible adverse effect. In the cases of undocumented over the counter use, Benylin could have contributed to a fall in one of the patients, and another, taking large regular doses of sodium bicarbonate (ENOs salts) which have a high sodium content, presented with decompensated heart failure. There were three cases of patients experiencing falls which could have been due to the potential hypotensive effects of diuretics, and a further fall in a patient taking diazepam. Several cases where the extra information may have been relevant when choosing medication concerned instances where patients were already taking paracetamol on a regular basis and would have been at risk from a coprescribed paracetamol containing product. In six subjects previous penicillin allergy was not recorded by the $A \& E$ SHO, which would have been important background information for the patient's manage- ment. However, patient-reported allergies to penicillins are often unreliable. ${ }^{13}$

Although pharmacists undoubtedly took a more detailed drug history, it may be unreasonable to expect $\mathrm{A} \& \mathrm{E}$ SHOs to take an extra 11 or more minutes obtaining such detailed histories for medical admissions. The pharmacist was aided in the interview by a structured questionnaire, which provided the necessary prompts for elucidating a full drug history. It may be useful to have just a few prompts incorporated onto the $\mathrm{A} \& \mathrm{E}$ card, covering important aspects of a medication history, such that a relatively small extra time commitment was involved.

Such a time commitment may also be impractical for hospital pharmacists, unless patients are carefully selected for interview. A further suggestion may be to enlist the help of community pharmacists to assess the drug treatment of selected patients who are sent home. ${ }^{14}$

\section{CONCLUSIONS}

Omissions in the recording of drug histories occurred in the A\&E department and some of these may have been clinically relevant. Where drug histories are recorded there was sometimes a failure to note potential drug related problems. The asking and noting down of a few simple questions by A\&E SHOs would screen out many potential problems without a large time commitment. Prompts could be included on the casualty card with spaces to note current prescribed medication, over the counter usage, previous adverse drug reactions, and potential drug related problems. A case could be made for pharmacists to take a drug history from elderly patients on regimens that are complex or difficult to identify.

1 Taylor KJ, Datta ML. Adverse drug reactions as a cause of hospital admission. Care of the Elderly 1992;4:110-6. Rawlins MD. Clinical pharmacology: adverse reactions to drugs. BMF 1981;282:974-6.

3 Monson RA, Bond CA. The accuracy of the medical record as an index of outpatient drug therapy. $\mathscr{F} A M A$ 1978; as an index

4 Dodds LJ. An objective assessment of the role of the pharmacist in medication and compliance history taking. Br f Pharm Pract 1981;3:12-17.

5 Price D, Cooke J, Singleton S, Feely M. Doctors unawareness of the drugs their patients are taking: a major cause of over prescribing. $B M \mathcal{F} 1986 ; 292: 100-2$.

6 Massey CA. Evaluation of the benefits of pharmacistacquired drug histories. Proc Guild Hosp Pharm 1987 25:80-1.

7 Badwoski SA, Rosenbloom D, et al. Clinical importance of pharmacist obtained medication histories using a validated questionnaire. Am f Hosp Pharm 1984;41:731-2.

8 Covington TR, Pfeiffer FC. The pharmacist-acquired medication history: clinical forum. Am $\mathcal{f}$ Pharm 1972;29. $692-5$

9 Dawson P, Gray S. Clinical significance of pharmacist obtained drug histories. Pharm $\mathcal{F}$ 1981;227:420.

10 Higham C. Drug history taking - a role for the ward pharmacist. Pharm $\mathcal{f} 1982 ; 228: 302-5$.

1 Wilson RS, Kabar HF. Pharmacist initiated patient drug histories. Am f Hosp Pharm 1971;28:49-53.

12 Campbell AJ, Borrie MJ, et al. Risk factors for falls. $f$ Gerontol Med Sci 1989;44:112-7.

13 Surtees SJ, Stockton MG, Gietzen TW. Allergy to penicillin: fable or fact? BMF 1991;302:11051-2.

14 Kimberlin CL, Berardo DH, et al. Effects of an education program for community pharmacists on detecting drugprogram for community pharmacists on detecting drug-
related problems in elderly patients. Med Care 1993; 31:451-68. 